Dust pollution

\section{The London Underground: time for a thorough clean-up?}

\section{R Colvile}

\section{Commentary on the paper by Seaton et al (see page 355)}

T he London Underground was for decades the envy of every capital city in the world. Forty year old trains were powered by electricity from a polluting oil fired power station. Tobacco smoking was permitted at stations and in some carriages. Levels and composition of dust on The Tube had been measured, and found to contain a variety of toxic substances including quartz from brake blocks, ${ }^{1}$ but concentrations perhaps did not seem so high compared with other workplace environments and even outdoor urban air at that time.

Today's trains use their electric motors to decelerate, so brake dust is much reduced. A new power distribution system allows energy to be returned to some sections of track, resulting in less heat and lower electricity consumption. Cleaner sources have replaced the oil fired power station, and smoking is banned. All these measures tackle air pollution at source, especially underground. So why are we increasingly worried about air quality on The Tube?

The Tube is a heavy engineering operation sharing a confined space with the public. While diesel emissions can give bus passengers a lungful of particles, the problem above ground is largely confined to highly localised pollution hotspots close to dense traffic. ${ }^{2}$ The volume of air for dilution outdoors is orders of magnitude greater than what can readily be achieved underground. In the tunnels and sub-surface stations, the accumulation of any pollutant has the potential to lead to high levels of exposure for large numbers of people.

Thanks to Seaton and colleagues' well designed study, ${ }^{3}$ we now arguably understand more about likely health effects of tunnel dust than about the richer if more dilute cocktail of particles above ground. Tunnel dust's similarity to welding fume, plus the likely protective effects of larger particle size, allow some reassurance to be offered to staff and passengers. Underground management have won a breathing space, while good science makes scaremongering more difficult.

Nevertheless, the recommendation based on the toxicity of the dust is that efforts to reduce levels should be continued. London Underground could probably be considered negligent to do nothing indefinitely. Yet to act hastily without thoroughly evaluating the options runs the risk of selecting a dust abatement measure that is far from cost effective. Until recently, a tunnel cleaning train went slowly round the system during the few hours each night when the track is not live. One hopes it is a coincidence that the median dust size underground corresponds to the particles that enjoy the greatest ability to pass through most filters... Tunnel cleaning might simply be shifting dust around and not removing very much. Clearing dust from one short section may also have little lasting effect where material migrates back from uncleaned areas upstream.

Health effects are not the only driver for dust abatement. Signalling equipment and cooling fans have to overcome continually getting dirty. The pollution is also visible as black grime on any light coloured surface underground, and sometimes a faint haze that can be discerned on looking along the length of a platform. It therefore contributes to London's reputation for still being polluted and unhealthy despite the improvements that have been made. The growth of London's economy and population has not been matched by sufficient investment for capacity of The Tube to keep pace with demand, resulting in a reputation for overcrowding and discomfort, especially in hot weather. In the media, tunnel dust and its possible effects on health are reported as part of this bigger story.

One application of Seaton and colleagues' findings might be quantification of benefits of dust abatement. There has been much debate recently about the cost per life saved of safety improvements on railways, ${ }^{4}$ which is usually rather high compared with less safe road transport. But the more tangible dust related costs of system unreliability, as well as willingness to pay for a pleasanter and cleaner Tube, may be less controversial and possible to calculate reasonably accurately.

So, how much does a good clean-up cost? The answer depends crucially on the problem of dust origin and movement alluded to above-how much of the dust is of recent, local origin compared with historical build-up of contamination? Surprisingly, this remains unknown. Such source apportionment determines what length of tunnel would need to be cleaned per night to deliver (for example) a 50\% reduction in time for 2012. ${ }^{56}$ Now that Seaton et al have provided such a clear toxicological assessment, the most urgent need for further research is to consider how to reduce levels. A combination of particle microphysics and engineering is required. As long as dust removal remains so poorly understood, staff and passengers will continue to be exposed to this unique air pollutant on London's unique mass transport system. It is therefore fortunate that Seaton et al did not identify any cause for serious concern.

Occup Environ Med 2005;62:354.

doi: 10.1136/oem.2004.018929

Correspondence to: $\operatorname{Dr} R$ Colvile, Faculty of Life Sciences, Imperial College London, South Kensington Campus, London SW7 2AZ, UK; r.colvile@imperial.ac.uk

Competing interests: none

\section{REFERENCES}

1 Health \& Safety Executive. Dust in the London Underground. London: HMSO, 1982.

2 Kaur S, Nieuwenhuijsen M, Colvile R. Personal exposure of street canyon intersection users to PM2.5, ultrafine particle counts \& carbon monoxide in Central London, UK. Atmospheric Environment. Submitted.

3 Seaton A, Cherrie J, Dennekamp M, et al. The London Underground: dust and hazards to health Occup Environ Med 2005;62:355-62.

4 Uff J, Lord Cullen. The Joint Enquiry into Train Protection Systems, Health \& Safety Commission 2001.http://www.hse.gov.uk/railways/spad/ lgril.pdf.

5 London 2012 Candidate City. Theme 14:Transport.http://www.london2012.org/en/ news/publications/Candidatefile/ Candidatefile.htm.

6 Mayor of London. Cleaning London's air: the mayor's air quality strategy, paragraphs 4G.24 to 4G.35. Greater London Authority, 2002 180-3, hitp://www.london.gov.uk/mayor/ strategies/air_quality/docs/chap_4.pdf. 